\title{
“A DESCRIPTIVE STUDY TO ASSESS THE KNOWLEDGE \& PRACTICE AMONG NURSES REGARDING NURSING MANAGEMENT OF SCHIZOPHRENIC PATIENTS AT PSYCHIATRIC CENTRE, S.M.S. MEDICAL COLLEGE HOSPITAL, JAIPUR, RAJASTHAN."
}

\author{
Mr. Pradeep Kumar Sharma
}

PhD Scholar JJTU. M.Sc. (N), Mental Health Nursing, Faculty, Govt. College of Nursing, Jaipur, Rajasthan, India

Corresponding Email: - pksharmapeethalpur@gmail.com

\begin{abstract}
Introduction: Mental and behavioral disorders are found in people of all regions, all countries and all societies. The psychiatric nurse observes all mentally ill patients and provides nursing care to all indoor patients.

In psychiatric centre the most of indoor patients are schizophrenic and psychiatric nurse involve in all therapies which are given to schizophrenic patients.

Method \& Material: The descriptive design was used in this study. 50 registered nurses worked at psychiatric centre, Jaipur were sampled through total enumeration sampling technique was used. A structured questionnaire was developed to assess knowledge regarding nursing management of schizophrenic patients and a checklist for practices of nursing management of schizophrenic patients.

Result: There is a significant relationship between knowledge scores and age, sex, academic qualification and professional work experience in psychiatric unit.There is a significant relationship between practice scores and age, sex, academic qualification, professional qualification and professional work experience in psychiatric unit.There is a significant positive correlation between knowledge and practice of nurses regarding nursing management of schizophrenic patients

Conclusion:-The general nurses have lack of knowledge \& practice regarding nursing management of schizophrenic patients. So for awareness among nurses regarding nursing management of schizophrenic patients, conduct a Orientation programme for nurses regarding nursing management of schizophrenic patients.
\end{abstract}

Key words: Registered nurses, nursing management of schizophrenic patients, psychiatric centre, Jaipur. 


\section{INTRODUCTION:}

Mental and behavioral disorders are found in people of all regions, all countries and all societies.

Schizophrenia is one of the commonest of serious mental disorders. The word schizophrenia is derived from two Greek words schizo+phren, Schizo means split and phren means mind. It is one major psychotic disorder having primary and secondary symptoms.

Nurses are the most important part of health care system. In field of psychiatry the nurses role is very important.

The psychiatric nurse observes all mentally ill patients and provides nursing care to all indoor patients.

In psychiatric centre the most of indoor patients are schizophrenic and psychiatric nurse involve in all therapies which are given to schizophrenic patients.

STATEMENT OF THE PROBLEM:

"A descriptive study to assess the knowledge \& practice among nurses regarding nursing management of schizophrenic patients at psychiatric centre, S.M.S. Medical college hospital, Jaipur, Rajasthan."

OBJECTIVES:-

1. To assess the Knowledge of nurses regarding nursing management of schizophrenic patients.
2. To assess the Practice of nurses regarding nursing management of schizophrenic patients.

3. To associate the knowledge of nurses regarding nursing management of schizophrenic patients with the selected demographic variables.

4. To associate the practice of nurses regarding nursing management of Schizophrenic patients with the selected demographic variables.

5. To find out the relationship between Knowledge and Practice of nurses regarding nursing management of Schizophrenic patients.

\section{RESEARCH HYPOTHESIS}

H1- There will be a significant relationship between knowledge of nurses regarding nursing management of Schizophrenic patients with their selected demographic variables.

H2- There will be a significant relationship between practices of nurses regarding nursing management of Schizophrenic patients with their selected demographic variables.

H3 - There will be a significant relationship between knowledge and practice of nurses regarding nursing management of Schizophrenic patients.

\section{METHODOLOGY}

The descriptive design was used in this study. 50 registered nurses worked at psychiatric centre, Jaipur were sampled 
through total enumeration sampling technique was used. Astructured questionnaire was developed to assess knowledge regarding nursing management of schizophrenic patients and a checklist for practices of nursing management of schizophrenic patients.

\section{STATISTICAL ANALYSIS}

Data was analyzed by using percentage, mean, mode, median and standard deviation c.v. etc. Chi square test was used to find out association between Knowledge and Practice of nurses regarding nursing management of Schizophrenic patients.

\section{RESULTS}

In the present study, majority of nurses were below 31-40 years of age [45\%], males [67.5\%], having senior secondary education level [47.5\%], G.N.M qualification [75\%], had professional experience below 10 years [42.5\%] and not attended any in service education program regarding nursing management of schizophrenic patients..

The findings reveal that majority of [70\%] nurses are obtained inadequate knowledge score i.e. (below 75\%).

Practice scores obtained by majority of [75\%] nurses were also inadequate practice (below 70\%).

Nurses are obtained highest knowledge scores were from age group of 31-40 years, females, M.Sc. nurses and with 1120 years of experience in psychiatric unit. Nurses are obtained highest practice scores were from age group of below 30 years, females, M.Sc. nurses and with less than 10 years of experience in psychiatric unit.

There is a significant relationship between knowledge scores and age, sex, academic qualification and professional work experience in psychiatric unit.

There is a significant relationship between practice scores and age, sex, academic qualification, professional qualification and professional work experience in psychiatric unit.

There is a significant positive correlation between knowledge and practice of nurses regarding nursing management of schizophrenic patients The present study may be replicated on a large sample covering the entire nurses regarding nursing management of schizophrenic patients, working at psychiatric wards of all medical colleges in Rajasthan, as well as other parts of the country to validate and generalize the findings.

A similar comparative study may be undertaken between nursing students and nursing personnel in Rajasthan and other parts of the country. 


\section{CONCLUSION}

The general nurses have lack of knowledge \& practice regarding nursing management of schizophrenic patients. So for awareness among nurses regarding nursing management of schizophrenic patients, conduct a Orientation programme for nurses regarding nursing management of schizophrenic patients.

\section{REFERENCES:}

1. Basavanthappa BT. Psychiatric mental health nursing. 1st ed. New Delhi: Jaypee Brothers Medical Publishers; 2007. p. 709-710.

2. Park K. Text book of preventive and social medicine. 18th ed. Jabalpur: M/s. Banarsidas Bhanot; 2005. p. 632.
3. Gail Wiscan Sturart. Principles and practice of psychiatric nursing. 8th ed. Kundli: Sanat Printers; 2005. p. 236242.

4. Lalitha K. Mental Health and Psychiatric Nursing. 2nd ed. Bangalore, Gajanana Publishers; 2000. p 244

5. WHO. Country Profile: Atlas, Geneva. (2001) p. 412-415. 